\title{
Utilization of Metallurgical Wastes in Indian Steel Industries
}

\author{
Shipa S K \\ Department of (Electrical \& Electronics Engineering) \\ (Bapuji Institute of Engineering Technology) \\ (Shamanur Road, Davangere, Karanataka 577004)
}

\begin{abstract}
The rapid development of metallurgical industry, leads to large amount of metallurgical solid waste. The slag, dust and sludge generated by integrated steel plants was called waste. These wastes contain some valuable resources and elements such as iron, zinc, lead, calcium, etc., which can be recovered and reused in steel making process or can be used as raw materials therefore the term waste has been replaced with "by-product" due to intensive re-utilization of these wastes. The company pursues the policy of three R's Recycle, Reduce and Reuse to manage its waste. The main objective of the companies is now to transform solid waste into wealth in order to benefit. This Paper gives various advanced techniques adopted by steel companies such as Jidal, TATA, JSW etc. in order to utilize metallurgical waste. By studying it is observed that almost all companies adopting maximum steps to utilize the metallurgical waste.
\end{abstract}

Keywords - By Product, Recycle, Reduce and Reuse.

\section{A. INTRODUCTION}

Steel sectors are one of the major waste producer .The steel plant solid wastes can be generated from process unit and pollution control units. Slag, dust,sludge, scrap, refractories, scale, muck and debris, etc. are the generated from steel making or from process unit. Non-process waste are waste materials like rubber, card-board, electric wire, glass, etc.To make steel, ironore is first mined from the ground. It is then smelted in blast furnaces where the impurities are removed and carbon is added. Simple definition of steel is "iron alloyed with carbon, usually less than 1\%." In steel industry all three types of waste i.e., solid, liquid and gases generated. The waste generated by steel industry not only causes health problems but also causes lot of environmental degradation. Therefore it becomes very important for the industries who are involved in the manufacture of steel to look for the methods that ensures safe disposal and recycling of waste. Sectors are already running out of raw material therefore they have invented new technology to handle those waste for sustainable development. New technologies seem to be more ecological and at the same time, more economical.

\section{B.TYPES OF WASTES GENERATION IN STEEL PLANT COMPLEX.}

Solid wastes like, hot metal pretreatment slag, dust, GCP sludge, mill scale, refractories, scrap, muck \& debris, etc. Liquid wastes like industrial effluent, oil, grease, etc. Gaseous wastes like flue gases, fume extraction, etc.

\section{ADVANTAGES OF RECYCLING AND UTILIZATION OF WASTES}

$>$ Economic advantages

$>$ Saving of raw materials

$>$ Conservation of resources

$>$ Better \& cleaner environment

$>$ Reduced cost of disposal

$>$ Conservation of energy

$>$ Strengthen laws by the Government

$>$ Community relation/Public image etc

\section{SOLID WASTE UTILIZATION}

In order to utilize steel slag, several experiments and developments have been tried and some of the successful means of utilization are described below.

1) Steel Slag

a). Slag Atomisation: Atomising Technology is a process that converts molten slag $\left(1300-1350^{\circ} \mathrm{C}\right)$ into small spherical balls (Precious slag ball-PS balls) with a diameter range of 0.1 to $4.5 \mathrm{~mm}$. It is called as Slag atomising technology (SAT).PS Ball have many applications. It is an environment-friendly material proved by Ministry of Environment. It has superior characteristics compared to sand or copper slag in its compressive strength, hardness and ant weathering. Fig. 1 shows the image of PS balls. Due to their higher specific gravity, PS balls can be used to obtain high density concrete[1]. High density concrete is useful in applications such as earthworks, breakwater blocks, foundations, road construction (Surface layer, sub base layer), radiation insulators and other cases as applicable. The higher flexural strength of concrete containing PS balls is a very important parameter making it suitable to be used as pavement material

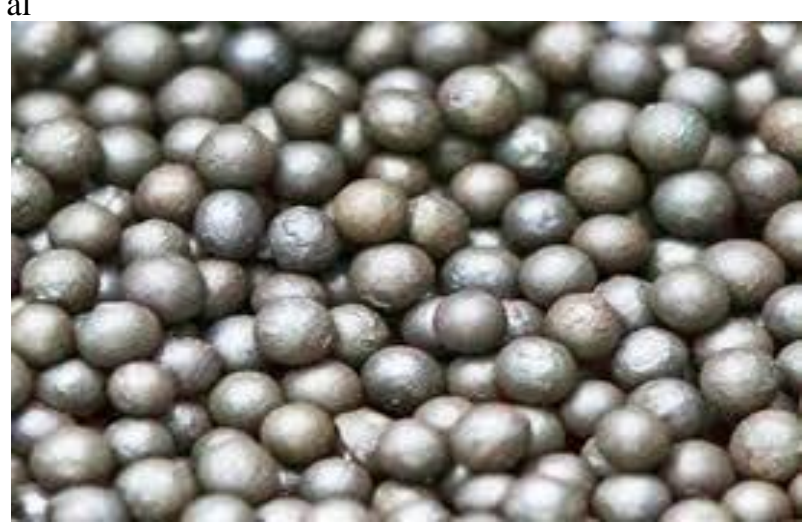

Fig.1 Image of PS balls 
2. Rail Ballast: Steel slag is hard, dense and resistant to both attrition and abrasion making it suitable for use as a railway ballast aggregate.

3.Road \& pavement material: SMS Slag has already been successfully used as road making aggregate in SAIL. Steel Plants like BSP, BSL and RSP in place of stone chips. The pavement are introduced in walkways, patios, driveways as shown in Fig. 2 .Slag mixed with fly ash has been successfully tried and being used for brick manufacture. streets, airport runways etc.

4. SMS Slag mixed with fly ash has been successfully tried and being used for brick manufacture.

5. Crushed SMS slag of size approx 300 mesh sizes can be used for soil conditioning. Tea and coffee plantations are potential customers.

6. Steel slag contains oxide of aluminium and iron combined with a calcium base which reacts to neutralize the $\mathrm{PH}$ of the waste water.

7. SMS slags have been successfully used for flooring tiles because of their good abrasive materials properties.

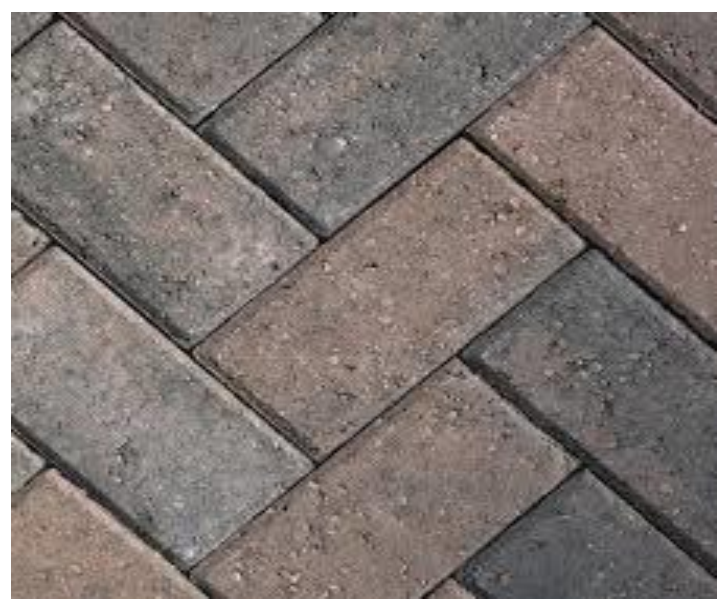

Fig 2. Concrete Pavement Blocks

b) SMS Shop dust:It collected from dedusting FES system of the SMS shop contains high $\%$ of $(\mathrm{Fe}>40 \%)$ and it is usable for reuse in sinter making plant.

c) Lime dolomite plant dust: Due to high content of $\mathrm{CaO} \&$ $\mathrm{MgO}$, these dust can be used for sinter making.

d) GCP Sludge: Sludge generated from BOF-GCP in rich in iron $(>40 \% \mathrm{Fe})$ and it dominantly constitutes $\mathrm{Fe} 2 \mathrm{O} 3$ and therefore, it can be used for sinter making.

\section{E .TOP STEEL INDUSTRIES IN INDIA}

Following Industries are the Top industries in India.

$>$ Jindal

$>$ Rashtriya Ispat Nigam Limited (RINL)

$>$ UTTAM GALVA STEEL LTD.

$>$ MSP STEEL PLANTS.

$>$ Essar Steel.

$>$ TATA Steel.

$>$ JSW Steel.

1.Jindal: In Jindal, the company pursues the policy of three R's- Recycle, Reduce and Reuse- for managing its waste. Some of the plans undertaken for effective solid waste management are:
i).Power generation from coal rejects fines and middling in AFBC boilers.Slag generated from blast furnace is $100 \%$ reused in cement manufacturing and brick making.Tailor made sinter plant to utilise $100 \%$ mill scale and flue dust generated in mills and blast furnace.SMS slag after granulation is used for road making. Fly ash generated is used for brick manufacturing and cement manufacturing.

ii). Ash utilisation:A captive brick plant has been established to produce around 4.0 lakh brick products/day for manufacturing of fly ash bricks. All construction activities of the company are done through these fly ash bricks. Measures have already been taken to achieve a level of $100 \%$ utilisation of fly ash. The ash is partly used for brick making, ash dyke rising, road and embankment construction, cement manufacturing.

iii).Impact of the pollution control measures taken on conservation of natural resources and consequently on the cost of production

By-product gases generated in Coke plant, Blast Furnace and Steel melting are recovered and clean gas is used as fuel in power generation and other units, thus reducing coal consumption.

iv).Centralised effluent treatment Plant (CETP) in operation to maximize reuse and recovery of treated waste water from different plant units.Mechanised road sweeping machine engaged to maintain housekeeping of plant roads.[2]

2.Rashtriya Ispat Nigam Limited (RINL)

The company been taken steps to reduce energy consumption by adopting several energy efficient technologies and initiatives during our expansion phase, including $100 \%$ coke dry quenching, $100 \%$ LD gas recovery, evaporative cooling systems in our rolling mills and a gas expansion turbine station in our blast furnace to recover the potential energy of blast furnace gas. These technologies have not only reduced energy consumption, but have also reduced greenhouse gas emissions by 13,000 tonnes annually. It is also participated in a number of environmentally friendly joint research projects, including a project attempting to remove carbon dioxide from flue gases by sequestration, which would result in reduced carbon dioxide emissions. RINL is a seven time recipient of the National Energy Efficiency Award given by the Ministry of Power for exemplary performance in energy conservation, and also received the Excellent Energy Efficient Unit award from the Confederation of Indian Industry for 2010-11. In 2011, it received a BS EN 16001:2009 certification from the Bureau Veritas for their energy Essar Steel's move towards 100 percent recycling of ferrous waste.

At a production rate of 7.2 MTPA, about 1000 MT iron bearing solid waste is generated every day. Of these, about 400 TPD has iron content of more than $65 \%$, and part of this is metallic iron.

Although these iron-rich material can be used directly in Sinter plant, it is economically more sustainable to charge them in steel melt shops. In addition, Sinter plant surfaces with operational issues like hot sinter discharge when metallic is charged with sinter raw material. Besides, such wastes cannot be directly fed into the steelmaking furnaces, and they need to be agglomerated before charging. 
3. Uttam Galva Steel Ltd.

An HR (Hot Rolled) coil is slit to the required width in a HR slitter. After this operation the material is processed in a pickling line to remove all the iron oxide scales. The pickling line is provided with a water seal and gas scrubber to ensure that no noxious vapours enter the environment.

Pickling lines remove any rust and scale from hot-rolled strips. The process is based on conveying the strip through hydrochloric acid baths to dissolve the surface oxides.

Hot Rolled (HR) coils

The waste pickle liquor ("WPL") generated during the processing of HR in the pickling line, is fed to the flushed bed reactor after achieving the required density by pumping it through a venturi. As the temperature in the reactor is very high the WPL is split into iron oxide and $\mathrm{HCl}$ gas and iron oxide is produced.The $\mathrm{HCl}$ gas, generated in the flush bed reactor, passes through a cyclone separator. Fine iron dust is dropped in the cyclone separator and the $\mathrm{HCl}$ gas moves to an absorber via a venturi. In the absorber, $\mathrm{HCl}$ gas moves upward and water is introduced thereby absorbing the $\mathrm{HCl}$ gas and producing hydrochloric acid. The concentrated acid is collected, stored and reused for pickling.

\section{MSP Steel Plant:}

To reduce the purchase metallurgical Coke requirement for Blast Furnace, steel Plant proposed to add new capacity to their existing Coke oven facilities to produce total 240,000 Tons of Metallurgical Coke per annum through Non-recovery Coke ovens with WHRB to produce power from the sensible heat of the coke oven flue gas. To utilize the excess Dolo char waste generated from existing Sponge Iron Kilns and to utilize the waste heat to be generated from Coke oven flue gas, it have envisaged to augment their Captive Power Plant capacity by $18 \mathrm{MW}$ and $15 \mathrm{MW}$ through Atmospheric Fluidized Bed Boiler and Waste Heat Boiler route respectively to generate steam for driving Turbines to produce electric power. Almost $95 \%$ of the additional fuel requirement after completion of expansion plan will be met from the in-plant fuel to be recovered in the form of Blast Furnace Gas (700Kcal/Nm3 ) and LD Converter gas (2000 $\mathrm{Kcal} / \mathrm{Nm} 3$ ) and balance $5 \%$ only to be met by pulverized imported Anthracite coal injection in the closed area $(6500 \mathrm{Kcal} / \mathrm{Kg})$. Thus there will be hardly any requirement of purchased fuel for expansion plan and most of the fuel will be clean gaseous fuel in the form of by-product gas. Closed circuit water system will be installed for all units wherever water is used as indirect coolant. Only make up water to be consumed to compensate the evaporation loss and water consumed in the process. 'Zero discharge' scheme will be adopted by utilizing the blow down water in quenching of pig iron and dust suppression system. Rain water harvesting scheme will also be adopted in the plant for water conservation..A suitable sized dump yard for dumping waste materials will also be created.

5.Essar Steel: The eco-friendly sand is essentially developed from slag, a by-product generated from iron-making furnaces. Slag sand is approved by BIS 2016 for use as fine aggregate in all construction applications. The initial and final strength of the concrete made using the slag sand is better compared to natural sand. It can be used in all construction activities and can replace river sand.This innovative slag sand, which is being produced in Essar Steel's Hazira facilit, will help protect our rivers from sand mining and associated problems.The product is aligned with the company's sustainability goals. Essar Steel also uses the coal fines and effluent gases generated from its pellet making operations for power generation and recycling treated water. It recycles almost all the waste water generated in its plants, and even has a paper recycling unit at Hazira. Coal fines generated at its pellet making units, and iron ore fines generated from the sinter plant are recycled and reused in the steelmaking process. Effluent gas from these units is also used in power generation. Essar Foundation launched its first pilot project on solid waste management in the three villages of Jakhar, Singach and Mithoi on 19 November 2016. As a part of this project, each of these three villages would run the following programmes:

> Awareness drive on solid waste management, stressing on the method and importance

$>$ Collection of waste from individual households

$>$ Segregation of waste into wet and dry

$>$ Disposal of waste in designated areas[2]

6. TATA Steel: Some steps taken by Tata Steel, $89.6 \%$ of solid waste generated from Steel Works is recycled or reused. $17 \%$ of the solid waste generated, amounting to approximately $6,12,300$ tonnes in 2008-09 was used to fill low-lying areas and for peripheral road construction around Jamshedpur.BF Slag (Solid Waste) generated is sells to cement factories

\section{F. CONCLUSION}

Steel sectors are one of the major waste producer, but they have developed various process by which most of the waste are again converted into economy. Getting value from a waste is always difficult, but it is the need and required to use those waste/scrap parts. Sectors are already running out of raw material therefore they have invented new technology to handle those waste for sustainable development.

\section{G REFERENCE}

[1] S .Sharath B C Gayana Krishna R Reddy and K Ram Chandar "Experimental investigations on performance of concrete incorporating Precious Slag Balls (PS Balls) as fine aggregates", Vol. 8 , No. 3 (2019) 239-246 in Advances in Concrete Construction.

[2] Iron \& Steel Review, Magazine published in June 27,2017. 